\title{
Article
}

\section{Producing food in English and Welsh prisons}

Devine-Wright, Hannah, Baybutt, Michelle and Meek, Rosie Available at http://clok.uclan.ac.uk/29613/

Devine-Wright, Hannah, Baybutt, Michelle ORCID: 0000-0002-3201-7021 and Meek, Rosie (2019) Producing food in English and Welsh prisons. Appetite, 143 (104433). ISSN 0195-6663

It is advisable to refer to the publisher's version if you intend to cite from the work. http://dx.doi.org/10.1016/j.appet.2019.104433

For more information about UCLan's research in this area go to http://www.uclan.ac.uk/researchgroups/ and search for <name of research Group>.

For information about Research generally at UCLan please go to http://www.uclan.ac.uk/research/

All outputs in CLoK are protected by Intellectual Property Rights law, including Copyright law. Copyright, IPR and Moral Rights for the works on this site are retained by the individual authors and/or other copyright owners. Terms and conditions for use of this material are defined in the policies page.

\section{CLoK}

Central Lancashire online Knowledge www.clok.uclan.ac.uk

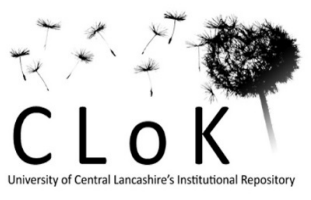




\section{Journal Pre-proof}

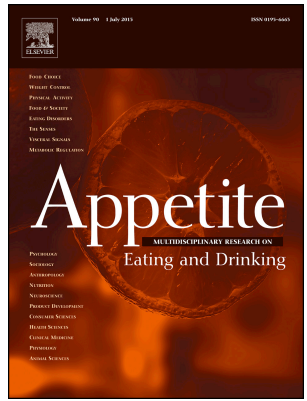

Producing food in English and Welsh prisons

Hannah Devine-Wright, Michelle Baybutt, Rosie Meek

PII: S0195-6663(19)30371-X

DOI: $\quad$ https://doi.org/10.1016/j.appet.2019.104433

Reference: $\quad$ APPET 104433

To appear in: Appetite

Received Date: 15 March 2019

Revised Date: 4 August 2019

Accepted Date: 26 August 2019

Please cite this article as: Devine-Wright H., Baybutt M. \& Meek R., Producing food in English and Welsh prisons, Appetite (2019), doi: https://doi.org/10.1016/j.appet.2019.104433.

This is a PDF file of an article that has undergone enhancements after acceptance, such as the addition of a cover page and metadata, and formatting for readability, but it is not yet the definitive version of record. This version will undergo additional copyediting, typesetting and review before it is published in its final form, but we are providing this version to give early visibility of the article. Please note that, during the production process, errors may be discovered which could affect the content, and all legal disclaimers that apply to the journal pertain.

(C) 2019 Published by Elsevier Ltd. 
Our reference: APPET 104433

Article reference: APPETITE_2019_347

Article title: Producing food in English and Welsh prisons

To be published in: Appetite

\section{Author names and affiliations}

Dr Hannah Devine-Wright ${ }^{1}$

Dr Michelle Baybutt ${ }^{2}$

Professor Rosie Meek ${ }^{3}$

${ }^{1}$ Placewise Ltd, Uffculme, Devon. EX15 3DR. United Kingdom. Hannah@placewise.org ${ }^{2}$ Healthy \& Sustainable Settings Unit, University of Central Lancashire, Preston, Lancashire. PR1 2HE. United Kingdom. MBaybutt@uclan.ac.uk

${ }^{3}$ Department of Law and Criminology, Royal Holloway, University of London. TW20 0EX. United Kingdom. R.Meek@rhul.ac.uk

Lead author: Title: $\quad \mathrm{Dr} \quad$ Forename: Hannah Surname: Devine-Wright Affiliation: Placewise Ltd. Address: Uffculme, Devon, EX15 3DR. UK Email: Hannah@placewise.org

Second author: Title: Dr Forename: Michelle Surname: Baybutt Affiliation: Healthy \& Sustainable Settings Unit, University of Central Lancashire, Preston, Lancashire. PR1 2HE. UK

Email: MBaybutt@uclan.ac.uk

Third author: Title Professor Forename: Rosie Surname: Meek Affiliation: Department of Law and Criminology, Royal Holloway, University of London. TW20 0EX. UK

Email: R.Meek@rhul.ac.uk 


\section{Journal Pre-proof}

\section{Abstract: Producing food in English and Welsh prisons}

Most prison food research focuses on aspects of consumption rather than production yet

farming, horticulture and gardening have been integral to the prison system in England and Wales for more than 170 years. This paper explores the interplay between penological, therapeutic and food priorities over the last fifty years through an examination of historical prison policies and contemporary case studies associated with the Greener on the Outside for Prisons (GOOP) programme. Findings are discussed in relation to how joined-up policy and practice can impact positively on whole population health and wellbeing within and beyond the prison setting. 


\section{Introduction}

While food plays a critical role in the physical and mental wellbeing of people in prison, impacting on many aspects of prison life such as culture, relationships and the construction of positive identities, it is often overlooked as a key feature of incarceration (WHO, 2015). Furthermore, within research and narratives of prison food about nutritional or dietary requirements, food habits or the meaning of food (e.g. Smoyer \& Lopes, 2017), to-date there has been an emphasis on the consumption rather than production of prison food which this paper seeks to address.

Between 1990 and 2019, the UK prison population almost doubled, it now stands at just over 82,500 (Ministry of Justice, 2019), representing the highest incarceration rate amongst western European jurisdictions (Sturge, 2018). Within the prison populations the most socio-economically disadvantaged communities, where levels of social exclusion are most marked, are significantly over represented (Ismail \& de Viggiani, 2018). Research revealing the strong association between offending behaviour and poor health, low levels of educational attainment and wider deprivation suggests a 'vicious cycle' with most prisoners coming from and returning to the poorest or most socially excluded sections of society (Bradshaw et al., 2004). Prisons therefore represent a key organisational setting for health promotion activities (Whitelaw et al., 2001), and not least for initiatives that seek to improve nutrition (Gray et al., 2018).

The prison service in England and Wales currently spends approximately f15m annually on prison food, of which the government requires $25 \%$ to be grown in the UK. For a budget of approximately $£ 2$ per prisoner per day, catering managers are required to source 
ingredients for three meals that can be described as "wholesome, nutritious, well prepared and served, reasonably varied and sufficient in quantity" (National Offender Management Service, 2010). With a focus on gardening and farming, this paper explores how penological, therapeutic and food priorities have shaped prison food production in England and Wales since 1970 using a combination of primary and secondary data including case studies, qualitative interviews and historical accounts.

Prison food production is a complex topic not least because terms (e.g. agriculture, farming, growing, horticulture and gardening) can have multiple, often loosely defined or interchangeable meaning and associated practices. For the sake of brevity and clarity, we have chosen three activities associated with prison food production: gardening, horticulture and farming, and to differentiate between them on the basis of scale, spatiality and scope. Gardening is a relatively small-scale activity (e.g. raised beds) that can be accommodated within the built environment including high security, or limited space prisons. Garden produce typically supplements the diet of the gardeners. Horticulture is a medium-scale, usually commercial activity that can be accommodated within the boundaries of lowergrade prisons subject to sufficient space to erect 'liminal' structures (e.g. greenhouses or polytunnels) proximal to the prison. These liminal structures extend the timescale over which seasonal produce (e.g. salad crops) can be grown as they offer a degree of protection (e.g. from bad weather) for plants and those who tend them. Farming typically involves commercial, large-scale crop growing and animal husbandry which enables it to meet the demand for fresh produce from multiple prisons. However, as the history of prison farming shows, commercial imperatives, although important, have neither been the sole nor the principal reason for large-scale, in-house food production (Wright, 2017). 


\section{Connecting Nature and Health}

The consistent message from a diverse body of research is that contact with the natural environment improves psychological health and mental well-being (e.g. Barton et al., 2016; Maller et al., 2006; Ward Thompson et al., 2012). Amongst disparate ways of connecting with nature, gardening and 'care farming' are heralded as a means to promote health, wellbeing and flourishing across the life-course for a wide range of disadvantaged and vulnerable people in diverse contexts (Elsey, Murray \& Bragg, 2016; Fournier, Geller \& Fortney, 2007; Hine, Peacock \& Pretty, 2008; Sempik, Aldrige \& Becker, 2005). Although there have been few robust, independent studies, reviews and qualitative studies suggest that prison gardening and farming can have a positive indirect impact on health and wellbeing through fostering a sense of connection to nature, a healthier diet, increasing opportunities for meaningful activity, social connectedness, relaxation or physical exercise (Fournier et al., 2007; Husk, Lovell \& Garside, 2018; Wagenfield et al., 2018).

The benefits of physical activity in both community settings and prison populations are well established (Meek, 2014; 2018) but traditionally such activity has been provided through access to the prison gym or exercise yard, with a focus on weight lifting and team sports. For example, the National Audit Office (2006) report on prisoner diet and exercise failed to consider the wider benefits of gardening as either a form of exercise or a way to address heavy reliance on convenience foods. However, at a time when older prisoners represent the fastest growing population within our prisons, there have been calls for a more diverse and creative physical activity offering in our prisons to ensure that more vulnerable, inactive 
or less physically abled prisoners are also able to benefit from the social, psychological and physical benefits (Meek, 2018). Non-exercise activities like gardening are widely acknowledged as a way to supplement existing opportunities available to people in prison to be physically active (Elger, 2009), with those who are least active most likely to benefit in terms of long-term health (Matthews et al., 2015).

Differentiating between the effects of physical activity and contact with nature can be difficult within contemporary studies of prison farming and gardening programmes (e.g. Brown et al., 2015) (Moran \& Turner, 2018), as is accounting for the positive effect of simply being outside (Elsey et al., 2016). For example, research amongst prison staff found that $84 \%$ reported that being outside was calming irrespective of how they used external spaces (e.g. for exercise, quiet contemplation, relaxation or respite) (Wagenfield et al., 2018). However, rather than trying to partial out the relative contribution of being outside, eating well, connecting with nature or physical exercise, a 'settings approach' seeks to understand how health promoting activities like gardening are embedded within institutional cultures, structures, processes and routines (Dooris, 2012).

\section{Prison Setting and Population}

Underpinned by a number of principles (e.g. equity, participation, empowerment, partnership and sustainability), the settings approach reflects an ecological model that takes account of the dynamic, complex interactions between personal, organisational and wider environmental factors that influence health (Dooris, 2009). Applying this framework to the the justice context, it is clear that that a health-promoting prison must be safe and secure, 
and underpinned by principles of human rights, respect and decency (Baybutt et al., 2014;

Department of Health, 2002). Imprisonment itself will not reduce the likelihood of reoffending and therefore activities must focus on improving skills and removing barriers, such as an absence of hope, that impede successful rehabilitation (Lindstrom \& Eriksson, 2006; Mann, Fitzalan Howard \& Tew, 2018). In an era of limited public spending it is argued that gardening is low cost, crucially offering the opportunity to bridge and 'join up' public health and criminal justice agendas to enhance learning and improve resettlement prospects (Baybutt \& Chemlal, 2015).

Good prison health concerns the whole of society with prisoners coming from and returning to the wider community. Therefore, accessing people in the environments in which they lead their lives and make life choices is an essential approach to tackling health inequalities and promoting public health. Wider benefits of good prison health includes lowering the costs of imprisonment by improving the health of the whole community; reducing public health expenditure; improving reintegration into society and reducing reoffending; reducing inequalities; and reducing the size of prison populations (WHO, 2015). It is argued therefore that the prison setting offers a unique opportunity to address health and social issues however, translating the health promoting prisons concept into practice is a real challenge (Baybutt \& Chemlal, 2015).

\section{History of Prison Food Production}

In England and Wales, prison farms have been producing food for consumption by prisoners and staff since 1852, when farming was introduced to HMP Dartmoor to provide a healthy and hard day's work in the open air (Lander, 1992). Considered an important means of 
providing 'useful and rewarding work for inmates', farms became an integral feature of the Borstal system (youth detention centres) as they became established in the early 1900s. Between 1939-1945 the 'Dig for Victory' campaign led to the intensive cultivation of household and prison gardens to produce quantities of vegetables for dietary use. Throughout the 1950s and 60s, the remit of the 'Farms and Gardens Section' included the 'control and supply of vegetables for dietary at Prisons and Borstal Institutions' alongside providing employment, education and training for prisoners (e.g. Farms and Gardens Section, 1955). To meet the demand for food across the prison service the service requisitioned poor quality, marginal land, that required extensive reclamation e.g. former WWII airfields. Thus, farming and penological practices coincided around notions of work as rehabilitative for land and prisoners.

In accordance with 'appreciative inquiry' (Liebling, Price \& Elliott, 1999) and a 'snowball' method of recruitment, twenty-two face-to-face semi-structured interviews were conducted between May 2015 and October 2016 with people who were knowledgeable about the history of prison food production in England and Wales. The interviewees consisted of six former and current uniformed staff (five male, one female), fourteen former and current civilian staff (eleven male, three female) and two serving prisoners (one male, one female). Of the uniformed staff, two had retired from the service (Director General and an Area Manager), and four were current staff (Head of Inmate Activities and Head of Operations and two prison officers with responsibility for horticulture). Of the civilian staff, eight had retired (two Heads of Farms and Gardens including Maurice Codd, the first civilian to become an Area Manager, three farm managers, two agricultural craftspeople and a farm manager's personal assistant). The six current civilian staff consisted of three people with 
responsibility for Land-Based Activities at prison headquarters, an agricultural craftsperson and two staff, a farm manager and a farm manager's personal assistant redeployed within the service after the prison farms were disbanded. Each interview was fully transcribed and established techniques of thematic coding (Braun \& Clarke, 2006) were used to draw out key opinions and perspectives.

Following the interviews, seven of the interviewees (two current and five former prison service employees) provided further relevant texts and audio-visual material (e.g. published and unpublished reports; national, local and professional media articles; audio recordings, photographs and letters from prisoners) which were 'closely read' (e.g. Brummett, 2018; Scholliers, 2013). Particular attention was paid to historical sources which were referenced by multiple interviewees, notably proceedings from annual farm management conferences held 1956-1995 (HM Prison Service, undated).

In the early 1970s penal policy around food production became explicitly therapeutic with the Department of Industries and Supply (DIS) (1971) describing farming as: "A dignified and healthy occupation which teaches good work habits, and broadens the outlook of many town dwellers and in one way or another affects us all in our daily lives...As distinct from the 'gardening' activities...the justification for commercial farming and horticultural activities within the Prison Service lies with the contribution it can make towards the wellbeing and rehabilitation of the inmate" (p.2). Prison farms, according to the staff who managed them in the 1970s, "not only taught about living things, but about life itself, and in so doing broadened horizons, extended capabilities, increased self-respect and gave pleasure and sustenance to many" (HM Prison Service, undated ${ }^{a}$, p.228). A year later it was suggested 
that "commercial farming could be abandoned and a policy of therapeutic farming adopted" (HM Prison Service, undated ${ }^{b}$, p.243). However, although the physical and mental health benefits of farming and horticulture, and to a lesser extent gardening, were widely acknowledged, these benefits remained largely anecdotal rather than empirically validated, for example 'For the urban dweller a period of working on a farm or similar activity can provide a therapeutic change, the mental and physical benefits of outdoor work are obvious and require no emphasis.' (HM Prison Service, 1997).

Food self-sufficiency, which had been promoted during the 'Dig for Victory' campaign, remained a key objective within prison policy. By the early 1990s, the Prison Service in England and Wales was able to supply commercial standard produce to all 147 prisons, enough to feed the entire prison population (47,000 prisoners). However, as the prison service entered a more punitive, privatised, 'postrehabilitation' era (Garland, 1991) those in charge of the prison service began to question the legitimacy and credibility of having farming and farmers at the heart of imprisonment (Wright, 2017). Rather than advocating food production as 'therapeutic' or 'hard work', a mechanism of reform or rehabilitation, the ruling assumption became one of 'prison works', a means of incapacitating and punishing to satisfy popular political demands for public safety and retribution (Garland, 1991).

Following a series of internal and external reviews, the integral prison food production system that included farms, horticulture, vegetable preparation units and a national food distribution network was disbanded. Between 2003-2006, Phil Wheatley, the Director General of the Prison Service between the years 2003-2010, who prior to joining the service 
had worked as a landscape gardener, authorised a controversial programme to replace traditional prison farms with horticultural facilities (McEwan, 2009; Wright, 2017). His testimony justifies this move with the statement: "When the population is going up and they say you have got to manage a bigger population then you think, well we are probably better off looking after prisoners than Suffolk Punch horses." (Interview Transcript, p.14, lines $36-39)$. By $2006,95 \%$ of prison farmland had been sold or returned to its original owners, food production had become contracted out to a small number of private companies and the therapeutic and penological value of commercially-oriented prison farming was largely forgotten (Wright, 2017).

\section{Growing food in prisons in England and Wales: the case of Greener on the Outside for}

\section{Prisons (GOOP)}

Despite nationwide privatisation of prison food production, a surprising quantity of farms and horticultural facilities as well as knowledgeable staff remain in the prison service. In 2008, shortly after centralised prison agriculture and horticulture in England and Wales ended, Greener on the Outside for Prisons (GOOP), a programme of therapeutic gardening, was established in the North-West of England. Working in partnership with individual prisons, GOOP sought to either extend the reach of existing provision or create new gardening projects.

The GOOP programme has been developed in an integrated way, explicitly working across the whole prison system in order to promote a rehabilitative culture. There have been a number of different mixed-method research studies assessing the benefits of the GOOP programme using prisons as case studies. Measures employed within the case studies have 
included tailored Green Gym (C questionnaires to assess physical activity and the Warwick Edinburgh Mental Wellbeing Scale (WEMWBS) to guage mental wellbeing amongst prisoners and staff in adult male and female prisons in the North West (Baybutt, Dooris \& Farrier, 2018; Baybutt, Farrier \& Dooris, 2012) as well as a process evaluation exploring 'what works and why'.

There are a wide range of examples of GOOP produce being used in education for both cooking skills and learning about the origins and different types of fresh grown food in recognition that when people in prison can learn and practise cooking, these skills may lead to employment during or following prison (WHO, 2015). By enabling participants to try the food they have grown (e.g. beetroots, cucumber, tomatoes, peppers, chillies and lettuce in salads) GOOP enables additional benefits such as an increased awareness of how to eat more healthily while in prison and beyond with families. GOOP works best when there is whole prison engagement that draws upon referral systems from healthcare or drug services for example to deliver a range of needs-led, locally determined gardening initiatives whereby key skills and accredited horticultural qualifications are embedded into the core of GOOP delivery; and, where produce can be used for education, returned back into the prison system through catering processes and/or linked into commercial activities such as sales to staff, visitors and the local community.

In the context of the current UK prison reform agenda that seeks effective and sustainable prisoner management and rehabilitation (Ismail \& de Viggiani, 2018) and against a backdrop of public sector constraint and concern about the high incidence of violence, suicide, self- 
harm and poor mental health among prisoners, GOOP has empirically demonstrated that gardening can benefit the physical and mental health and wellbeing of prisoners and make a significant contribution to the creation of safe, secure, supportive and health-enhancing environments (Baybutt et al., 2018; Farrier, Baybutt and Dooris, 2019; Farrier and Kedwards, 2015). These impacts are increasingly widely recognised as being the result of joined-up 'whole system' working. Consequently, GOOP's whole system approach centred around gardening and the production of prison food is increasingly informing national policy and practice (e.g. Meek, 2018) with GOOP becoming 'mainstreamed' within public sector prisons in Northern England.

\section{The Future of Producing Food in Prisons in England and Wales}

Currently, over half of the state prisons in England and Wales (70 of 118) have some form of horticultural activity taking place, and 44 public sector prisons are engaged in commercial horticultural (Coveney, 2019). Procurement strategies are being revised and in regions like the north-west, establishments are re-introducing gardening as a means of supplying their own and nearby prison kitchens with produce, whilst offering meaningful employment and training suitable for a wide range of prisoners.

Despite the perception that prison horticulture is not as space efficient as classrooms or workshops for occupying prisoners (Moran \& Turner, 2018), horticultural facilities are included in plans for Glen Parva, a new Cat C prison, due to open in 2021. The $f 170 \mathrm{~m}$ rebuild will accommodate 1600 inmates and the main blocks are being designed around allotments and polytunnels. Rather than obfuscate the social and human costs of incarceration (Jewkes \& Moran, 2015), 'greening' the prison estate can foster real and 
enduring connections, with nature, staff and other prisoners, connections that are known to improve prisoners' psychosocial outcomes (Baybutt et al., 2012; 2018; Smoyer, 2015; Wright, 2017). Integrating horticulture and gardening in the prison estate enables prisoners to 'cut produce in the morning, eat it in the evening' and challenges dominant narratives about prison food systems as uncaring, punishing and disempowering (Smoyer \& Lopes, 2017).

\section{Discussion}

Globally, prisoners tend to come from marginalised and socially disadvantaged sections of society and exhibit a high incidence of ill health, linked to social exclusion and multiple complex needs (Baybutt et al., 2018). Therefore, as a setting, prisons offer a unique opportunity to invest in the health of disadvantaged and marginalised populations and address health inequalities and social exclusion (Woodall, 2016).

Growing fresh, seasonal produce for use in prison kitchens is a purposeful and meaningful activity with a wide range of benefits for the individual, the institution and wider society. There are many pathways whereby growing food as a leisure, therapeutic or commercial activity, can enhance prisoner health and wellbeing, whether it be through improving life skills, creating a sense of ownership, building relationships between participants or in enabling physical exercise (e.g. Baybutt et al., 2012, 2018; Brown et al., 2015; Grimshaw \& King, 2002; Meek, 2018; Wright, 2017).

Participation in farming, horticulture and gardening in the prison setting can provide a key role in mitigating health inequalities. However, there is a need for a paradigm shift to 
deliver new (and resurrect old) ways of delivering and reframing 'health' in order to embrace holistic approaches to wellbeing and impact beyond the prison setting. Such a shift is evident in the current National Partnership Agreement for Prison Healthcare in England, 2018 -2021, between the Ministry of Justice, HM Prisons and Probation Service, Public Health England, Department of Health and Social Care and the National Health Service which focuses on three core, shared objectives: improving the health and wellbeing of people in prison and reducing inequalities; reducing reoffending and supporting rehabilitation by addressing health related offending behaviour; and supporting access to and continuity of care throughout the prison estate, pre-custody and post-custody into the community.

Historical and contemporary accounts of food growing initiatives within and across prisons suggest that farming, horticultural and gardening can make a notable contribution to achieving these objectives. Whilst there has been a tendency to focus on how imprisonment extends beyond the confines of the prison (e.g. Foucault, 1977; Moran, Turner \& Schliehe, 2018), there has been a paucity of research on how food production practices, like the 'Dig for Victory' campaign, influenced prison policy and practices. The successful production of food in prison, that impacts positively on health and wellbeing in its broadest sense, is dependent on bridging across systems and a commitment to joined-up working both within and beyond the prison (Baybutt \& Chemlal, 2016). There is an historical precedence for this with prison farms and gardens (Wright, 2017) which we argue represents an opportunity currently being missed in the design and running of our contemporary prisons. Gardening, horticulture and agriculture demonstrate a legitimate opportunity to bridge and develop public health, criminal justice and sustainability agendas with historical and contemporary 
initiatives demonstrating that participating in the production of prison food can enhance physical and mental health, promote learning and skills, increase employability prospects and promote models of good citizenship (Baybutt \& Chemlal, 2016; Farrier et al., 2019; Wright, 2017).

\section{References}

Barton, J., Bragg, R., Wood, C., \& Pretty, J. (Eds.) (2016) Green Exercise: Linking Nature, Health and Well-being. London: Routledge.

Baybutt, M., Acin E., Hayton P., \& Dooris, M. (2014) Promoting Health in Prisons:A Settings Approach. In: World Health Organization (Ed) Prisons and Health. Copenhagen: WHO Regional Office for Europe, pp.180-184.

Baybutt, M., \& Chemlal, K. (2016) Health-promoting Prisons: Theory to Practice. Global Health Promotion, 23, 66-74.

Baybutt, M., Dooris, M., \& Farrier, A. (2018) Growing Health in Prison Settings. Health Promotion International. doi: 10.1093/heapro/day037.

Baybutt, M., Farrier, A., \& Dooris, M. (2012) Target: Wellbeing. Pan-Regional Prisons Programme: Health, Inclusion and Citizenship. Final Report. Preston: UCLan / Groundwork UK. Available at https://academic.oup.com/heapro/advancearticle/doi/10.1093/heapro/day037/5020761 [accessed 8 March 2019].

Bradshaw, J., Kemp, P., Baldwin, S., \& Rowe, A. (2004) The Drivers of Social Exclusion: Review of the Literature for the Social Exclusion Unit in the Breaking the Cycle Series. London: Office of the Deputy Prime Minister.

Braun, V., \& Clarke, V. (2006) Using Thematic Analysis in Psychology. Qualitative Research in Psychology, 3, 2, 77-101.

Brown, G., Bos, E., Brady, G., Kneafsey, M., \& Glynn, M. (2015) A Summary Report of an Evaluation of the Master Gardener Programme at HMP Rye Hill: An Horticultural Intervention with Substance Misusing Offenders. Coventry: Coventry University.

Brummett, B.S. (2018) Techniques of Close Reading (2 ${ }^{\text {nd }}$ Edition). New York: Sage.

Coveney, C. (2019) Personal communication. Public Sector Prison Industries, Catering and PE: Land Based Activity.

Department of Health (2002) Health Promoting Prisons: A Shared Approach. London: Department of Health. Available from: 
http://webarchive.nationalarchives.gov.uk/20130107105354/http://www.dh.gov.uk/prod_c onsum_dh/groups/dh_digitalassets/@dh/@en/documents/digitalasset/dh_4034265.pdf.

DIS Policy (1971) Farms and Gardens: Historical Background. Unpublished draft document dated 9/2/1971.

Dooris, M. (2009) Holistic and Sustainable Health Improvement: the Contribution of the Settings-based Approach to Health Improvement. Perspectives in Public Health. Royal Society for Public Health, 129, 1.

Dooris, M. (2012) Settings for Promoting Health. In: Jones, L. \& Douglas, J. (Eds) Public Health: Building Innovative Practice. London: Sage.

Elger, B.S (2009) Prison Life, Television, Sport, Work, Stress and Insomnia in a Remand Prison. International Journal of Law and Psychiatry, 32, 2, 74-83.

Elsey, H., Murray, J., \& Bragg, R. (2016) Green Fingers and Clear Minds: Prescribing 'Care Farming' for Mental Illness. British Journal of General Practice, 99-100.

Farms and Gardens Section (1955). Position at $31^{\text {st }}$ March, 1955. Unpublished document supplied by Maurice Codd, Head of HMP Farms and Gardens 1982-1991.

Farrier, A., Baybutt, M., \& Dooris, M. (2019) Mental Health and Wellbeing Benefits from a Prisons Horticultural Programme. International Journal of Prisoner Health. doi: 10.1108/IJPH-11-2017-0055.

Farrier, A., \& Kedwards, J. (2015) Impact Report: Greener on The Outside For Prisons. UCLan / Target: Wellbeing. https://www.uclan.ac.uk/research/explore/projects/assets/GOOPImpact-Report.pdf [accessed $21^{\text {st }}$ February 2019]

Foucault, M. (1977) Discipline and Punish: The Birth of the Prison. Translated by Alan Sheridan. London: Penguin.

Fournier, A.K., Geller, E.S., \& Fortney, E.V. (2007) Human-Animal Interaction in a Prison Setting: Impact on Criminal Behaviour, Treatment Progress, and Social Skills. Behavior and Social Issues, 16, 89-105.

Garland, D. (1991) Sociological Perspective on Punishment. Crime and Justice, 14, 115-165.

Gray, S., Jones, M., Means, R., Ormer, J., Pitt, H., \& Salmon, D. (2018) Inter-sectoral Transfer of the Food for Life Settings Framework in England. Health Promotion International, 33, 781790.

Grimshaw, R., \& King, J. (2002). Horticulture in Secure Settings. Reading: Thrive.

Hine, R., Peacock, J., \& Pretty, J (2008) Care Farming in the UK: Evidence and Opportunities. Report for the National Care Farming Initiative (UK). University of Essex. 
HM Prison Service (1997) Prison Service Agri Business Review (PSABR) (January 1997) Unpublished document.

HM Prison Service (undated) Farm Conference History 1956-1975 Volume 1. Unpublished document.

HM Prison Service (undated) Farm Conference History 1976-1995 Volume 2. Unpublished document.

Husk, K., Lovell, R., \& Garside, R. (2018) Prescribing Gardening and Conservation Activities for Health and Wellbeing in Older People. Maturitas, 110, A1-A2.

Ismail, N. and de Viggiani, N. (2018) What are the Barriers Prison Governors and Staff Face in Implementing the Healthy Prisons Agenda? In: South West Public Health Scientific Conference 2018, Bristol, UK, 13 March 2018. Bristol, UK: Centre for the Development and Evaluation of Complex Interventions for Public Health Improvement (DECIPHer), pp. 1-14 Available from: http://eprints.uwe.ac.uk/36233

Jewkes, Y., \& Moran, D. (2015) The Paradox of the 'Green' Prison: Sustaining the Environment or Sustaining the Penal Complex? Theoretical Criminology, 19, 4, 451-469.

Lander, N. (1992) The Convicts Who Reap What They Have Sown. Financial Times Weekend, 3-4 October, p.vii.

Liebling, A., Price, D., \& Elliott, C. (1999) Appreciative Inquiry and Relationships in Prison. Punishment \& Society, 1, 1, 71-98.

Lindstrom B., \& Eriksson, M. (2006) Contextualizing Salutogenesis and Antonovsky in Public Health Development. Health Promotion International, 21, 238-244.

McEwan, G. (2009) From Bars to Blooms. Horticultural Week, Feb 13, 23-24.

Maller, C., Townsend, M., Pryor, A., Brown, P., \& St. Leger, L. (2006) Healthy Nature Healthy People: 'Contact with Nature' as an Upstream Health Promotion Intervention for Populations, Health Promotion International, 21, 1, 45-54.

Mann, R., Fitzalan Howard, F., \& Tew, J. (2018) What is Rehabilitative Prison Culture? Prison Service Journal, 235, 3-9.

Matthews, C.E., Moore, S.C., Sampson, J., Blair, A., Xiao, Q., Keadle, S.K., Hollenbeck, A., \& Park, Y. (2015) Mortality Benefits for Replacing Sitting Time with Different Physical Activities. Medicine and Science in Sports and Exercise, 47, 9, 1833-1840.

Meek, R. (2014) Sport in Prison: Exploring the Role of Physical Activity in Correctional Settings. Abingdon: Routledge. 
Meek, R. (2018) A Sporting Chance: An Independent Review of Sport in Youth and Adult Prisons. London: Ministry of Justice.

Ministry of Justice (2019) Prison Population Statistics. Population Bulletin: Weekly 22 February 2019. London: Ministry of Justice.

Moran, D., \& Turner, J. (2018) Turning Over a New Leaf: The Health-enabling Capacities of Nature Contact in Prison. Social Science \& Medicine.

https://doi.org/10.1016/i.socscimed.2018.05.032.

Moran, D., Turner, J. \& Schliehe, A. K. (2018) Conceptualizing the Carceral in Carceral Geography. Progress in Human Geography, 42, 5, 666-686.

National Audit Office (2006) HM Prison Service: Serving Time: Prisoner Diet and Exercise. Report for the Comptroller and Auditor General. London: Stationary Office.

National Offender Management Service (NOMS) (2010). Prison Service Instruction 44/2010: Catering Operating Manual. Meals for Prisoners in Custody. London: NOMS.

Scholliers, P. (2013) Food Recommendations in Domestic Education. Belgium 1890-1940. Paedogogica Historica - International Journal of the History of Education, 49, 5, 645-663.

Sempik, J., Aldrige, J., \& Becker, S. (2005) Health, Wellbeing and Social Inclusion. Therapeutic Horticulture in the UK. The Policy Press: Bristol.

Smoyer, A. (2015) Feeding Relationships: Foodways and Social Networks in a Women's Prison. Journal of Women and Social Work, 30, 1, 26-39.

Smoyer, A. B., \& Lopes, G. (2017) Hungry on the Inside: Prison Food as Concrete and Symbolic Punishment in a Women's Prison. Punishment and Society, 19, 2, 240-255.

Sturge, G. (2018) UK Prison Population Statistics. Commons Library Briefing 23 July 2018. Briefing Paper CBP-04334.

Wagenfield, A., Stevens, J., Toews, B., Jarzembowski, S., Ladjahasan, N., Stewart, J., \& Raddatz, C. (2018) Addressing Correctional Staff Stress through Interaction with Nature: a New Role for Occupational Therapy. Occupational Therapy in Mental Health, 34, 3, 285-304.

Ward Thompson, C., Roe, J., Aspinall, P., Mitchell, R., Clow, A., \& Miller, D. (2012) More Green Space is Linked to Less Stress in Deprived Communities: Evidence from Salivary Cortisol Patterns. Landscape and Urban Planning, 105, 3, 221-229. DOI: 10.1016/j.landurbplan.2011.12.015.

Whitelaw, S., Baxendale, A., Bryce, C., MacHardy, L., Young, I., \& Witney, E. (2001) 'Settings' Based Health Promotion: A Review. Health Promotion International, 16, 4, 339-53. 
World Health Organisation Regional Office for Europe (WHO) (2015) Food Systems in Correctional Settings. A Literature Review and Case Study. WHO: Copenhagen, Denmark.

Woodall, J. (2016) A Critical Examination of the Health Promoting Prison Two Decades On. Critical Public Health, 26, 615-621.

Wright, H. (2017) Outside Time: A Personal History of Prison Farming and Gardening. Uffculme: Placewise Press. 